\title{
Prevalence, Phenotypic Spectrum, and Modes of Inheritance of Gonadotropin-Releasing Hormone Receptor Mutations in Idiopathic Hypogonadotropic Hypogonadism*
}

\author{
M. BERANOVA, L. M. B. OLIVEIRA, G. Y. BÉDÉCARRATS, E. SCHIPANI, \\ M. VALLEJO, A. C. AMMINI, J. B. QUINTOS, J. E. HALL, K. A. MARTIN, \\ F. J. HAYES, N. PITTELOUD, U. B. KAISER, W. F. CROWLEY, JR., AND \\ S. B. SEMINARA
}

Reproductive Endocrine Unit, Harvard-wide Reproductive Endocrine Sciences Center, Massachusetts General Hospital (M.B., L.M.B.O., M.V., J.E.H., K.A.M., F.J.H., N.P., W.F.C., S.B.S.), Boston, Massachusetts 02114; Endocrine-Hypertension Division, Brigham and Women's Hospital and Harvard Medical School (G.Y.B., U.B.K.), Boston, Massachusetts 02115; Endocrine Unit, Massachusetts General Hospital (E.S.), Boston, Massachusetts 02114; Department of Endocrinology and Metabolism, All India Institute of Medical Sciences (A.C.A.), New Delhi, India 110029; and Department of Pediatrics, Division of Pediatric Endocrinology, New York Hospital-Cornell Medical Center (J.B.Q.), New York, New York 10021

\begin{abstract}
Mutations in the GnRH receptor $(G N R H R)$ have been described as a cause of reproductive failure in a subset of patients with idiopathic hypogonadotropic hypogonadism (IHH). Given the apparent rarity of these mutations, we set out to determine the frequency and distribution of GNRHR mutations in a heterogeneous population of patients with IHH who were well characterized with respect to diagnosis, phenotype, and mode of inheritance and to define their distribution within the receptor protein.

One hundred and eight probands with IHH were screened for mutations in the coding sequence of GNRHR. Forty-eight of the 108 patients had a normal sense of smell, whereas the remaining 60 had anosmia or hyposmia (Kallmann syndrome). Exon segments in the GNRHR were screened for mutations using temperature gradient gel electrophoresis, and all mutations were confirmed by direct sequencing.

Five unrelated probands ( 3 men and 2 women), all normosmic, were documented to have changes in the coding sequence of the GNRHR. Two of these probands were from a subgroup of 5 kindreds consistent with a recessive mode of inheritance, establishing a GNRHR mutation frequency of 2 of $5(40 \%)$ in patients with normos-
\end{abstract}

mic, autosomal recessive IHH. The remaining 3 probands with GNRHR mutations were from a subgroup of 18 patients without evidence of familial involvement, indicating a prevalence of 3 of 18 $(16.7 \%)$ in patients with sporadic IHH and a normal sense of smell.

Among the five individuals bearing GNRHR mutations, a broad spectrum of phenotypes was noted, including testicular sizes in the male that varied from prepubertal to the normal adult male range. Three probands had compound heterozygous mutations, and two had homozygous mutations. Of the eight DNA sequence changes identified, four were novel: Thr ${ }^{32} \mathrm{Ile}, \mathrm{Cys}^{200} \mathrm{Tyr}$, Leu ${ }^{266} \mathrm{Arg}$, and $\mathrm{Cys}^{279} \mathrm{Tyr}$. COS-7 cells transiently transfected with complementary DNAs encoding the human GNRHR containing each of these four novel mutations failed to respond to $\mathrm{GnRH}$ agonist stimulation.

We conclude that 1 ) the spectrum of phenotypes in patients with GNRHR mutations is much broader than originally anticipated; 2) the frequency of GNRHR mutations may be more common than previously appreciated in familial cases of normosmic $\mathrm{IHH}$ and infrequent in sporadic cases; and 3) functional mutations of the GNRHR are distributed widely throughout the protein. (J Clin Endocrinol Metab 86: 1580-1588, 2001)
$\mathrm{I}^{\mathrm{N}}$ N THE CLINICAL syndrome of idiopathic hypogonadotropic hypogonadism $(\mathrm{IHH})$, affected individuals present with delayed sexual development and inappropriately low gonadotropin and sex steroid levels in the absence of anatomical

Received September 18, 2000. Revision received November 30, 2000. Accepted December 6, 2000.

Address all correspondence and requests for reprints to: Stephanie Seminara, M.D., Reproductive Endocrine Unit, Bartlett Hall Extension 505, Massachusetts General Hospital, Boston, Massachusetts 02114. Email: seminara.stephanie@mgh.harvard.edu.

* This work was supported by the NIH National Center for Infertility Research (U54-HD-29164), the Harvard-wide Reproductive Endocrine Sciences Center (U54-HD-28138) at Massachusetts General Hospital and Harvard Medical School, NIH Grant RO1-HD-19938 (to U.B.K.), The Fulbright Commission (to M.B.), and Grant GA AV CR 78/A7020809 from the Grant Agency of the Czech Academy of Sciences (to M.B.). or functional abnormalities of the hypothalamic-pituitary axis. There are many subtypes of $\mathrm{IHH}$, including congenital $\mathrm{IHH}$ with anosmia [Kallmann syndrome (KS)] and IHH with adrenal insufficiency (adrenal hypoplasia congenita). Isolation of the gene responsible for X-linked KS (KAL) has led to a pathophysiological model correlating GnRH deficiency with abnormal olfactory bulb development (1-3). Mutations in the $\mathrm{X}$-linked gene for adrenal hypoplasia congenita, $D A X 1$, have also uncovered the crucial role of this orphan nuclear hormone receptor at multiple levels of the reproductive axis (4-6). Despite these discoveries, until recently little has been known about the genes that cause isolated $\mathrm{IHH}$ without anosmia or adrenal insufficiency.

The GnRH receptor gene (GNRHR, 4q21.2), encodes a seven-transmembrane domain $G$ protein-coupled receptor, 
but lacks the intracellular carboxyl-terminus typically seen in other members of this family $(7,8)$. Although an obvious candidate gene for $\mathrm{IHH}$, the nearly universal response of such patients to exogenous pulsatile GnRH initially made the candidacy of this gene seem unlikely (9). However, 3 yr ago, compound heterozygous mutations in the GNRHR were identified in a family with IHH (10). Now, numerous compound heterozygotes (10-14) and one homozygous (15) GNRHR mutation(s) have been described, causing subtypes of IHH varying from complete to partial resistance to GnRH.

The purpose of this study was to determine the prevalence of GNRHR mutations in a large population of well phenotyped patients with IHH (classified according to mode of inheritance) and establish genotype/phenotype correlations where possible. These studies demonstrate that GNRHR mutations can cause a broad range of reproductive phenotypes. GNRHR mutations, which appear to be distributed throughout the receptor, account for a larger proportion of both familial and sporadic cases of IHH than previously appreciated.

\section{Experimental Subjects}

\section{In vivo studies}

The diagnosis of IHH was based on the absence of spontaneous puberty by age $18 \mathrm{yr}$ and hypogonadal sex steroid levels (testosterone, $\leq 3.5 \mathrm{nmol} / \mathrm{L}$; estradiol, $\leq 73 \mathrm{pmol} / \mathrm{L}$ ) in the setting of inappropriately normal or low gonadotropin levels. In 65 of our 108 patients $(60 \%)$, additional evidence for a diagnosis of IHH was provided by 1) the absence of normal pulsatile gonadotropin secretion during 12-24 h of frequent (every $10 \mathrm{~min}$ ) blood sampling $(16,17) ; 2)$ normal basal and stimulated levels of TSH, PRL, GH, and cortisol on baseline and stimulation testing; and 3) no evidence of a mass lesion on imaging of the hypothalamic-pituitary region.

One hundred and eight unrelated probands from well characterized pedigrees were screened for mutations of the GNRHR. Patients were divided into three diagnostic categories: 1) idiopathic, congenital $\mathrm{IHH} / \mathrm{KS}(\mathrm{n}=87), 2)$ partial $\mathrm{IHH} / \mathrm{KS}(\mathrm{n}=14)$, and 3) acquired or adult-onset IHH $(\mathrm{n}=7)$. Patients were categorized as having partial IHH if low amplitude LH pulses were detectable during every $10 \mathrm{~min}$ blood sampling using modified Santen and Bardin pulse analysis or if the clinical history was consistent with partial pubertal development. Patients were categorized as having adult-onset IHH if they had undergone age-appropriate spontaneous sexual maturation by history (with proven paternity in some cases), but subsequently developed isolated IHH without an identifiable cause (18).

Fifty healthy volunteers (consecutive donors to the Massachusetts General Hospital blood bank) were also screened for mutations of the GNRHR.

\section{Modes of inheritance}

Genetic criteria were used to establish the likely mode of disease transmission as outlined in previous analyses (19). A family was classified as X-linked if only males were affected and unaffected females could be considered carriers. There could be no male to male transmission. A family was classified as autosomal recessive if all affected individuals were members of the same generation and included at least one female. Consanguinity provided additional support for this designation. A family was classified as autosomal dominant if direct transmission of the phenotype was demonstrable across generations, even if incomplete expressivity was present. Male to male transmission was considered definitive evidence for dominant inheritance. Delayed puberty and isolated anosmia were used as surrogate markers of the phenotype (19).

\section{Clinical phenotyping: baseline frequent sampling}

When possible, patients were admitted to the General Clinical Research Center of the Massachusetts General Hospital for phenotyping studies. Blood samples were collected every $10 \mathrm{~min}$ for $12-24 \mathrm{~h}$ for measurement of LH in 65 of the 108 patients. Pulsatile hormone secretion was assessed using the modified version of the Santen and Bardin method as previously described $(20,21)$. Gonadotropin responses to a single bolus of $100 \mu \mathrm{g}$ GnRH were also assessed. This study was approved by the subcommittee on human studies of the Massachusetts General Hospital; all subjects gave informed consent before participating.

\section{Materials and Methods}

\section{In vivo studies}

The serum LH and FSH concentrations of patients 1, 2, 3, and 5 were determined by one of two methods. 1) Immunoassays were calibrated against the Second International Reference Preparation of human menopausal gonadotropin (WHO 71/223) (22-24), with a minimal detectable dose of 0.8 IU (WHO 71/223)/L. Inter- and intraassay coefficients of variation were less than $10 \%$. Free- $\alpha$ subunit was measured by a monoclonal antibody RIA, using a highly purified $\alpha$-subunit of hCG as the standard $(25,26) .2)$ A microparticle enzyme immunoassay was performed using the automated Abbott AxSYM system, with the Second International Reference Preparation as the reference standard. The assay sensitivity for both $\mathrm{LH}$ and FSH was $1.6 \mathrm{mIU} / \mathrm{mL}$. The intraassay coefficients of variation (CVs) for LH and FSH were less than $7 \%$ and $6 \%$, respectively, with interassay CVs for both hormones of less than $7.4 \%$ Serum testosterone concentrations were measured using the Coat-ACount RIA kit (Diagnostic Products, Los Angeles, CA), which had intraand interassay $\mathrm{CVs}$ of less than $10 \%$. Estradiol $\left(\mathrm{E}_{2}\right)$ was measured by the AxSYM system (Abbott Laboratories, Chicago, IL), which had an analytical sensitivity of $36.7 \mathrm{pmol} / \mathrm{L}$ and a functional sensitivity of 73.4 pmol/L. The intraassay CV was less than $6.4 \%$ with an interassay CV less than $10.6 \%$.

\section{In vitro studies}

Mutational analysis. Genomic DNA was extracted from peripheral blood leukocytes or cultured white blood cells. Melting map analysis was performed for each exon fragment using Winmelt software (Bio-Rad Laboratories, Inc., Hercules, CA). When necessary, exon fragments were split, and primers for exon amplification were selected using Lasergene software (DNASTAR, Inc., Madison, WI). A 40-mer GC clamp [(GC)n CGCCCGCCGCGCCCCGCGCCCGCCCCGCCGCCCCCGCCCC] was attached to the 5 '-end of either the forward or the reverse primer to prevent strand melting. Three sets of primers were used to amplify exon 1: sense, 5'-ACACAAGGCTTGAAGCTCTGTCCCT-3'; antisense, 5' (GC)n TCTTTCTTCTGTGTCCACTTCTGA-3'; sense, 5'-CCACTCTGACCTTGTCTGGAAAG-3'; antisense, 5'-(GC)n AGCTTTAGATAACTGAGAACTTTGC-3'; and sense, 5'-AACATCTGACCTTAGCCAACCTG-3'; antisense, 5'-(GC)n CAAGGTAACAGAACAGAGCCAGAA-3'. One primer pair was used to amplify exon 2: sense, $5^{\prime}$ (GC)n AGGAGCTTAGAAATTGCTTTAGGTA-3'; antisense, 5'-TGCTATTTAAAAACTGCCCACAA-3'. Two primer pairs were used to amplify exon 3: sense, 5'-(GC)n GCTGTCTTCCTTTTTGTCCACTTTG-3'; antisense, 5'-CAATACCAAATCCTAGGACATAG-3'; and sense, 5' CACTTCATTTACTGTCTGCTGGAC-3'; antisense, $5^{\prime}$-(GC)n ATTCATTACCTTACCCTTCTTCATA- $3^{\prime}$. Reactions were performed in a final volume of $100 \mu \mathrm{L}$ containing $50 \mathrm{pmol}$ of each PCR primer, $200 \mu \mathrm{mol}$ of each deoxy-NTP, $2.5 \mathrm{U}$ Taq polymerase, and $10 \mathrm{mmol} / \mathrm{L}$ Tris- $\mathrm{HCl}(\mathrm{pH}$ 8.3). PCR reactions were carried out for 35 cycles: denaturing at $94 \mathrm{C}$ for $30 \mathrm{~s}$, annealing at $53-58 \mathrm{C}$ for $30 \mathrm{~s}$, and elongation at $72 \mathrm{C}$ for $30 \mathrm{~s}$. The quality and predicted molecular size of each PCR product were assessed by electrophoresis through a $1 \%$ agarose gel.

\section{Temperature gradient gel electrophoresis (TGGE)}

Given the large number of individuals screened for mutations, TGGE, a mutation detection method that can separate two DNA fragments that differ in sequence by as little as a single base substitution, was employed $(27,28)$. The TGGE apparatus is a horizontal acrylamide slab gel (Diagen, Dusseldorf, Germany) placed on a horizontal aluminum platform per- 
fused with water at a specified temperature gradient maintained by a digitally controlled heater bath (NESLAB Instruments, Portsmouth, $\mathrm{NH})$. Using the denaturation information obtained from the Winmelt profile analysis software, the optimal temperature gradient and running time for each amplified exon of the GNRHR were determined using a diagonal TGGE. Once the conditions for each exon were optimized, each PCR product was denatured and renatured in the absence or presence of the comparable PCR product from genomic DNA of a healthy volunteer to examine homo- or heterozygotic mutations. Samples with a final volume of $10 \mu \mathrm{L}$ were denatured (95 C, $5 \mathrm{~min}$ ), allowed to reanneal (55 C, $10 \mathrm{~min}$ ), and analyzed in parallel on a polyacrylamide gel. Electrophoresis was performed at $280 \mathrm{~V}$. Gels were then silver stained to allow the identification of DNA. PCR products that revealed an abnormal pattern, i.e. the presence of heteroduplexes in addition to the homoduplexes, were subjected to bidirectional DNA sequence analysis using either the same primers as those used for PCR amplification or nested primers.

\section{Functional studies of the GnRH receptor}

All cell culture reagents were supplied by Life Technologies, Inc. (Gaithersburg, MD). GenePorter reagent was obtained from Gene Therapy System (San Diego, CA), myo- $\left[2-{ }^{3} \mathrm{H}\right]$ inositol was purchased from NEN Life Science Products (Boston, MA), GnRH agonist (desGly ${ }^{10}\left[\mathrm{D}-\mathrm{Ala}^{6}\right] \mathrm{GnRH}$ ethylamide) was obtained from Sigma (St. Louis, $\mathrm{MO})$, and AG-X8 resin was purchased from Bio-Rad Laboratories, Inc. (Hercules, CA).

\section{Site-directed mutagenesis}

A hemagglutinin protein (HA)-tagged human GNRHR (hGNRHR) complementary DNA clone provided by Dr. Thomas Gudermann (29) was used as a template for generating $h G N R H R$ mutants. To generate the $\mathrm{Thr}^{32}$ Ile $h$ GNRHR mutant, the Thr codon ACC was replaced with the Ile codon ATC using the QuickChange site-directed mutagenesis kit (Stratagene, La Jolla, CA) and a pair of complementary mutagenic primers (sense, 5'-CAACCTCCCCACTCTGATCTTGTCTGGAAAAGATCCG3'; antisense, 5'-CGGATCTTTTCCAGACAAGATCAGAGTGGGGAGGTTG-3') according to the manufacturer's protocol. To generate the other three mutants, two-stage PCR-based mutagenesis was performed. To generate the $\mathrm{Cys}^{200} \mathrm{Tyr}$ mutant, the Cys codon TGC was replaced with the Tyr codon TAC using the following primers: sense, $5^{\prime}$-TAACACACTACAGTTTTTCACAAT-3'; and antisense, 5'-ATTGTGAAAAACTGTAGTGTGTTA-3'. To generate $\mathrm{Leu}^{266} \mathrm{Arg}$, the Leu codon CTA was replaced with the Arg codon CGA using the following primers: sense, 5'-CTGAAGACTCGAAAAATGACGGTT-3'; and antisense, 5'-AACCGTCATTTTTCGAGTCTTCAG-3'. To generate Cys ${ }^{279}$ Tyr, Cys (TGC) was replaced with $\operatorname{Arg}(\mathrm{TAC})$ with the following primers: sense, $5^{\prime}$ ATTTACTGTCTACTGGACTCCCTA-3'; and antisense, 5'-TAGGGAGTCCAGTAGACAGTAAAT- $3^{\prime}$. The sequence of the mutated hGNRHR was confirmed by bidirectional sequence analysis.

\section{Immunofluorescence detection of tagged GnRH receptors}

To determine the expression of the natural and mutant GnRH receptors, COS-7 cells were plated on glass-bottom 35-mm tissue culture dishes (MatTek Corp., Ashland, MA) and transiently transfected with 2 $\mu \mathrm{g}$ wild-type or mutant $h G N R H R$ constructs using GenePorter. After $48 \mathrm{~h}$, cells were rinsed with PBS, fixed for $30 \mathrm{~min}$ at room temperature with $4 \%$ formaldehyde, washed with PBS, and blocked with $1 \%$ BSAPBS for $30 \mathrm{~min}$ at room temperature. After blocking, cells were washed with PBS, incubated overnight at $37 \mathrm{C}$ with $5 \mu \mathrm{g} / \mathrm{ml}$ anti-HA-fluorescein antibody (clone 12CA5, Roche Molecular Biochemicals, Indianapolis, IN), washed four times with phosphate-buffered saline, and examined using a Bio-Rad Laboratories, Inc. (MRC-1024 multiphoton system), confocal laser microscope.

\section{Inositol phosphate (IP) assay}

The protocol used for measurement of total IP accumulation was an adaptation of that described by Panchenko et al. (30). COS-7 cells were transiently transfected by electroporation with $2 \mu \mathrm{g} /$ well wild-type or mutant $h G N R H R$ constructs and seeded into six-well tissue culture plates. After $24 \mathrm{~h}$, cells were incubated in inositol-free DMEM for $2 \mathrm{~h}$, with subsequent addition of $2 \mu \mathrm{Ci} /$ well myo-[2- $\left.{ }^{3} \mathrm{H}\right]$ inositol, followed by the addition of $10 \mathrm{mmol} / \mathrm{L} \mathrm{LiCl} 15 \mathrm{~min}$ later. Cells were further incubated for $14 \mathrm{~h}$ and stimulated with $100 \mathrm{nmol} / \mathrm{L} \mathrm{GnRH}$ agonist for $45 \mathrm{~min}$. Cells were extracted on ice twice with $20 \mathrm{mmol} / \mathrm{L}$ formic acid. Lysates were neutralized to $\mathrm{pH} 7.5$ with $7.5 \mathrm{mmol} / \mathrm{L}$ HEPES and $150 \mathrm{mmol} / \mathrm{L}$ $\mathrm{KOH}$ and centrifuged at $14,000 \times g$ for $2 \mathrm{~min}$. After the protein content was measured (Coomassie Plus protein assay reagent, Pierce Chemical Co., Rockford, IL), supernatants were loaded onto a 0.5-mL AG-X8 resin anion exchange column previously equilibrated with $2 \mathrm{~mL} 1 \mathrm{~mol} / \mathrm{L}$ $\mathrm{NaOH}, 2 \mathrm{~mL} 1 \mathrm{~mol} / \mathrm{L}$ formic acid, and $5 \times 5 \mathrm{~mL} \mathrm{ddH} \mathrm{O}_{2} \mathrm{O}$. The columns were then washed with $5 \mathrm{~mL} \mathrm{ddH_{2 }} \mathrm{O}$ followed by $5 \mathrm{~mL} 5 \mathrm{mmol} / \mathrm{L}$ borax and $60 \mathrm{mmol} / \mathrm{L}$ sodium formate, and IP was eluted with $3 \mathrm{~mL} 0.9 \mathrm{~mol} / \mathrm{L}$ ammonium formate and $0.1 \mathrm{~mol} / \mathrm{L}$ formic acid. A $500-\mu \mathrm{L}$ aliquot was counted, the counts were corrected for protein content, and results were expressed as the fold increase compared with the control plasmid (pcDNA3).

\section{Results}

In vivo studies: subjects and mode of inheritance

A total of 108 probands were examined for mutations in the GNRHR. Table 1 shows the breakdown of the individuals into diagnostic subcategories. Forty-eight patients had $\mathrm{IHH}$ with normal olfaction. Sixty patients had IHH and anosmia/ hyposmia (Kallmann syndrome). Although the vast majority of patients in each subcategory had congenital disease, seven patients had adult-onset IHH. Fourteen patients across both subgroups had partial variants of the condition.

The same 108 patients were also classified according to their presumed mode of inheritance, maintaining the dis-

TABLE 1. Breakdown of $\mathrm{HH}$ patients according to diagnosis

n GNRHR mutants

\begin{tabular}{|c|c|c|}
\hline \multicolumn{3}{|l|}{ Hypogonadotropic hypogonadism } \\
\hline \multicolumn{3}{|l|}{ Congenital HH } \\
\hline Autosomal recessive & 5 & 2 \\
\hline Autosomal dominant & 8 & 0 \\
\hline X-Linked & 0 & 0 \\
\hline $\begin{array}{l}\text { Unknown (either autosomal or } \\
\text { X-linked) }\end{array}$ & 1 & 0 \\
\hline Sporadic & 18 & 2 \\
\hline \multicolumn{3}{|l|}{ Adult onset } \\
\hline Sporadic & 4 & 0 \\
\hline \multicolumn{3}{|l|}{ Partial variants } \\
\hline Partial HH-sporadic & 1 & 0 \\
\hline Fertile eunuch-sporadic & 3 & 1 \\
\hline No pedigree information & 8 & 0 \\
\hline Total & 48 & 5 \\
\hline \multicolumn{3}{|l|}{ Hypogonadotropic hypogonadism + anosmia } \\
\hline \multicolumn{3}{|l|}{ Kallmann syndrome } \\
\hline Autosomal recessive & 4 & 0 \\
\hline Autosomal dominant & 11 & 0 \\
\hline X-Linked & 3 & 0 \\
\hline $\begin{array}{l}\text { Unknown (either autosomal or } \\
\text { X-linked) }\end{array}$ & 1 & 0 \\
\hline Sporadic & 29 & 0 \\
\hline IHH but in a family with KS-dominant & 1 & 0 \\
\hline IHH but in a family with KS-recessive & 2 & 0 \\
\hline Delayed puberty + anosmia-dominant & 1 & 0 \\
\hline Delayed puberty + anosmia-sporadic & 1 & 0 \\
\hline \multicolumn{3}{|l|}{ Partial variants } \\
\hline Partial KS-dominant & 1 & 0 \\
\hline Partial KS-sporadic & 2 & 0 \\
\hline Fertile eunuch variant-sporadic & 3 & 0 \\
\hline No pedigree information & 1 & 0 \\
\hline Total & 60 & 0 \\
\hline
\end{tabular}


tinction between normosmic and anosmic individuals. No pedigree information was available for a total of 9 individuals.

Familial cases. Of the 48 patients with congenital hypogonadotropic hypogonadism and normal olfaction, 5 were classified as autosomal recessive. GNRHR mutations were identified in 2 of these 5 families (patients 1 and 4; Table 1). Stated alternatively, $40 \%$ of normosmic hypogonadotropic hypogonadism probands whose pedigrees were consistent with an autosomal recessive mode of inheritance were found to have a mutated GnRH receptor. In 2 other autosomal recessive families, parents of the affected individuals were members of a consanguineous union, but there were no females among the affected subjects; both probands were negative for mutations in GNRHR. Six probands with hypogonadotropic hypogonadism and anosmia (in either the proband or family member) were also classified with an autosomal recessive mode of inheritance. However, no GNRHR mutations were identified in these individuals. No GNRHR mutation was identified in any other familial case of $\mathrm{IHH}$.

Nonfamilial cases. Of the nonfamilial cases (i.e. sporadic), a total of 18 individuals with normosmic IHH were studied. Two patients (no. 2 and 3) were found to have mutations. One patient (no. 5) with a partial variant of the condition was also found to have a mutation. Twenty-nine patients with sporadic $\mathrm{KS}$ were also studied; no mutations were identified. In total, the percentage of mutations in all patients with nonanosmic IHH was 5 of 48 , or $10.4 \%$. If noncongenital cases are excluded (i.e. adult onset), the percentage rises to 5 of 41 , or $12.2 \%$.

Clinical phenotype. Table 2 summarizes the clinical phenotypes of the five patients found to have GNRHR mutations. Three of the five patients were male. Patients 2 and 5 were evaluated at the Reproductive Endocrine Unit of Massachusetts General Hospital, whereas patient 4 was evaluated offsite. Frequent blood sampling in the General Clinical Research Center in both patients 2 and 5 revealed an apulsatile LH pattern. However, as summarized in Fig. 1, there were striking differences between the two men on gonadal examination. Patient 2 had testicular volumes of 1.4 and 2 cc, whereas patient 5 had testicular volumes of 15 and $17 \mathrm{cc}$. The testicular size of patient 4 at the time of presentation is unknown.

Differences between the female patients affected with GNRHR mutations were also apparent (Table 2). Although patient 1 presented with small breasts, patient 3 was noted to have Tanner III breasts at initial examination. Patient 1 had low gonadotropin and $\mathrm{E}_{2}$ levels. However, patient 3 had LH of $6.9 \mathrm{mIU} / \mathrm{mL}$, FSH of $8.9 \mathrm{mIU} / \mathrm{mL}$, and $\mathrm{E}_{2}$ of $139.5 \mathrm{pmol} / \mathrm{L}$. In contrast to the male patients, patients 1 and 3 had low amplitude pulses on baseline frequent sampling.

\section{In vitro studies}

Mutational analysis. Six nucleotide sequence abnormalities were described in five patients. Four changes were novel. Figure 2 diagrams the corresponding amino acid changes against the other mutations previously reported in the literature.
In patient 2 a cytosine in exon 1 was changed to thymidine at position 95, resulting in a threonine being replaced by isoleucine at residue 32 ( $\left.\mathrm{Thr}^{32} \mathrm{Ile}\right)$ near the junction of the $\mathrm{N}$-terminus and the first transmembrane domain. In the same patient exon 2 contained a guanine to adenine mutation at position 599, resulting in a cysteine being replaced by a tyrosine at amino acid $200\left(\mathrm{Cys}^{200} \mathrm{Tyr}\right)$ in the second extracellular loop.

In patient 3 a thymidine in exon 3 was changed to a guanine at nucleotide 797, causing a leucine to be replaced by an arginine at residue $266\left(\mathrm{Leu}^{266} \mathrm{Arg}\right)$ in the third intracellular loop. In exon 1 a mutation of an adenine to a guanine changed glutamine at residue 106 into an arginine $\left(\mathrm{Gln}{ }^{106} \mathrm{Arg}\right)$ in the first extracellular loop. This mutation has been previously described (10).

Patient 4 was one of two patients to have a homozygous mutation. A guanine was changed to an adenine at position 836, resulting in a cysteine being replaced by a tyrosine (Cys $\left.{ }^{279} \mathrm{Tyr}\right)$ in the sixth transmembrane domain.

Patient 5 contained the homozygous mutation Gln ${ }^{106} \mathrm{Arg}$. Patient 1 contained the compound heterozygotic mutations Gln ${ }^{106} \mathrm{Arg}$ and $\mathrm{Arg}^{262} \mathrm{Gln}$, both of which have been previously described $(10,31)$.

Polymorphisms. Some patients were found to have changes in the coding sequence of GNRHR of unknown significance. One individual with congenital IHH was found to be heterozygous for a GNRHR mutation ( $\mathrm{Arg}^{262} \mathrm{Gln}$ ). TGGE and sequencing of the remaining exons failed to identify a second coding sequence abnormality. One individual was found to have a change in the last base pair of exon 2 (nucleotide 741), changing a cytosine to a thymidine; however, this coding change was conservative with the amino acid histidine remaining at position 247. Again, no coding sequence abnormality was found in the remaining exons. In 3 additional cases, individuals were positive on TGGE, but subsequent sequencing localized the base pair change to the intron between exons 1 and 2. Because this change occurred in 2 of the 50 healthy volunteers, it would appear that this change has no influence on the IHH/KS phenotype. One normal volunteer was also found to be heterozygous for the $\mathrm{Gln}{ }^{106} \mathrm{Arg}$ mutation.

Functional studies of the mutant receptors. The presence of $h$ GNRHR proteins at the cell surface of COS-7 cells transiently transfected with plasmids encoding wild-type and mutant $h$ GNRHR constructs was determined by immunocytochemistry. Confocal fluorescence microscopy revealed a similar cellular presence of wild-type and mutant receptors in each case (Table 2$)^{1}$

The ability of the receptors to transduce a signal after GnRH agonist stimulation was assessed by measuring IP accumulation, an indicator of phospholipase C activity. Stimulation of COS-7 cells transiently transfected with wild-type $h G N R H R$ construct resulted in a 5.2-fold increase in intracellular IP levels, whereas all four of the novel mutant $h$ GNRHRs failed to respond to GnRH agonist stimulation (Table 2 and Footnote 1).

\footnotetext{
${ }^{1}$ Bédécarrats, G. Y., M. Beranova, F. Kada, S. B. Seminara, P. M. Corin, and U. B. Kaiser, manuscript in preparation.
} 


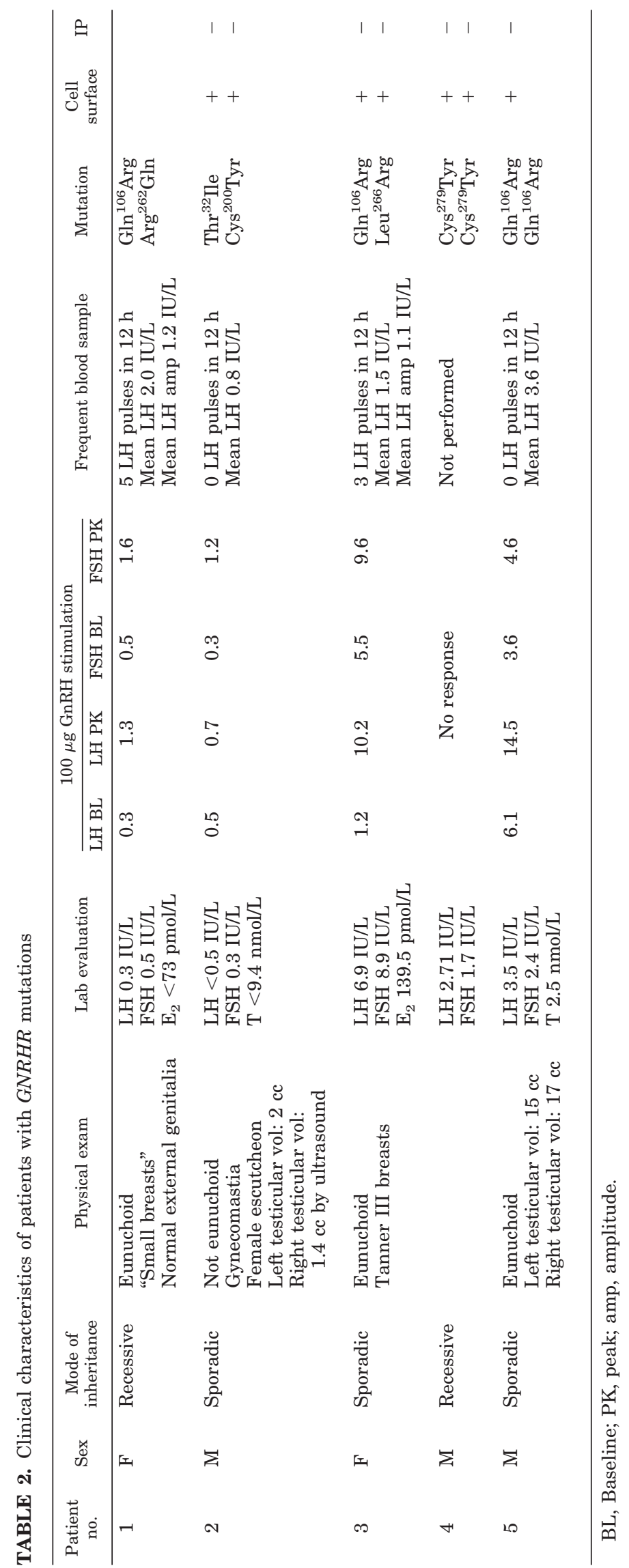




\section{Patient 2}

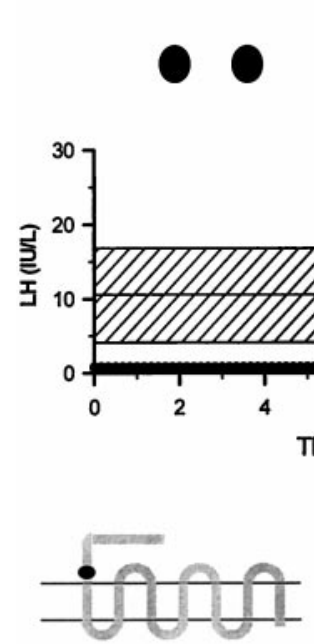

Thr32lle
Testes: 1.4-2 cC

Pooled FSH: 2.7 IU/L
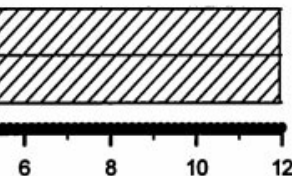

TIME (hrs)

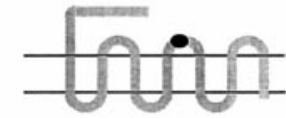

Cys200Tyr
Patient 5
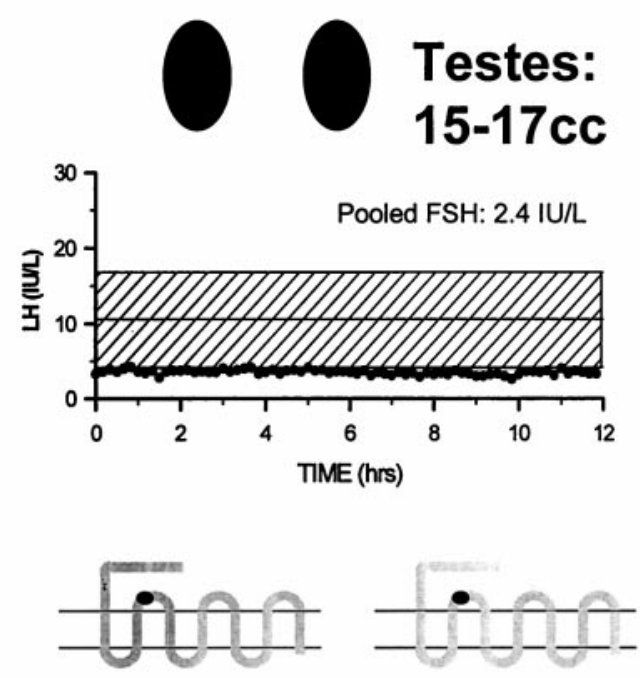

GIn106Arg

GIn106Arg

FIG. 1. Comparison of 2 patients (no. 2 and 5) with respect to testicular volume (TV), neuroendocrine profile, and GNRHR mutations. The graphs represent serum LH levels drawn every $10 \mathrm{~min}$ for $12 \mathrm{~h}$. The shaded area represents the normal range for LH levels as defined in 20 normal men (16).

\section{Discussion}

This screening study of a large and well characterized population of hypogonadotropic patients for mutations in the coding sequence of the GnRH receptor demonstrates that 1) patients with GNRHR mutations manifest a broad spectrum of phenotypes; 2) GNRHR mutations account for $40 \%$ of autosomal recessive IHH in subjects with a normal sense of smell;3) GNRHR mutations also occur in individuals with sporadic disease, but with a lower frequency; and 4) GNRHR mutations do not occur in patients with $\mathrm{IHH}$ and defects in olfaction. Four novel mutations in the receptor were also identified in this study. Despite cellular expression and presence on the cell surface, Thr ${ }^{32} \mathrm{Ile}, \mathrm{Cys}^{200} \mathrm{Tyr}, \mathrm{Leu}^{266} \mathrm{Arg}$, and $\mathrm{Cys}^{279}$ Tyr hGNRHR mutants were unable to respond to $\mathrm{GnRH}$ stimulation in vitro and resulted in loss of receptor function. Given the breadth of phenotypes described in this study, this report raises questions about the role of $\mathrm{GnRH}$ induced gonadotropin stimulation.

The GnRH receptor is a member of the rhodopsin-like G protein-coupled receptor family. Activation of these receptors is associated with conformational changes that facilitate coupling with $\mathrm{G}$ proteins and allow the receptor to transition between inactive and active states (32). Site-directed mutagenesis and conformational modeling have been used to study the effects of specific changes within the receptor; however, correlating mutations within the GNRHR-coding sequence to changes in structural conformation and to specific clinical phenotypes has been challenging.

Within the receptor protein, mutations have been described in the amino-terminus, first extracellular loop, transmembrane domains 3-7, and third intracellular loop (10-15). This study is the first to describe a mutation, $\mathrm{Cys}^{200} \mathrm{Tyr}$, in the second extracellular loop. All of the mutations described in this study resulted in a loss of receptor function. Moreover, an HA tag was used on the mutant constructs to demonstrate that the decreases in IP accumulation were not due to loss of $h G N R H R$ cell surface expression.

An important finding of this study is that mutations that cause the same functional changes in the GNRHR can lead to strikingly different clinical phenotypes. Nowhere is the breadth of phenotypes more dramatic than in two of the male patients described in this study (patients 2 and 5). Both patients have $\mathrm{IHH}$ and an apulsatile LH secretory pattern. Patient 2 has prepubertal testes, whereas patient 5 has a testicular size in the normal male range. Individuals such as patient 5 with hypogonadism but normal sized testes (with or without spermatogenesis) have been termed fertile eunuchs, a phrase originally coined to reflect a primary pituitary deficiency of LH, but normal FSH secretion $(33,34)$. Although patient 2 is a novel compound heterozygote (Thr ${ }^{32} \mathrm{Ile}, \mathrm{Cys}^{200} \mathrm{Tyr}$ ), patient 5 has a homozygous GNRHR mutation (Gln ${ }^{106} \mathrm{Arg}$ ) that has been described previously to reduce GnRH binding and IP signaling (10). Therefore, Gln ${ }^{106}$ Arg mutants may be capable of transmitting GnRH signal, albeit in a reduced fashion. How this signal results in normal testicular growth is not clear.

Pooled FSH samples during patient 5's frequent sampling study revealed a level of $2.4 \mathrm{IU} / \mathrm{L}$. Could this FSH be sufficient to account for patient 5's normal testicular size? Patient 2 had a similar pooled FSH level of 2.7 IU / L and yet had prepubertal-sized testes. Caron reported a patient with a GNRHR mutation and an FSH level of 3.3 IU/L (normal range, 1.2-11) with bilateral cryptorchidism and testicular volume less than 3 (12). As several assays of unknown com- 


\section{hGnRH Receptor}

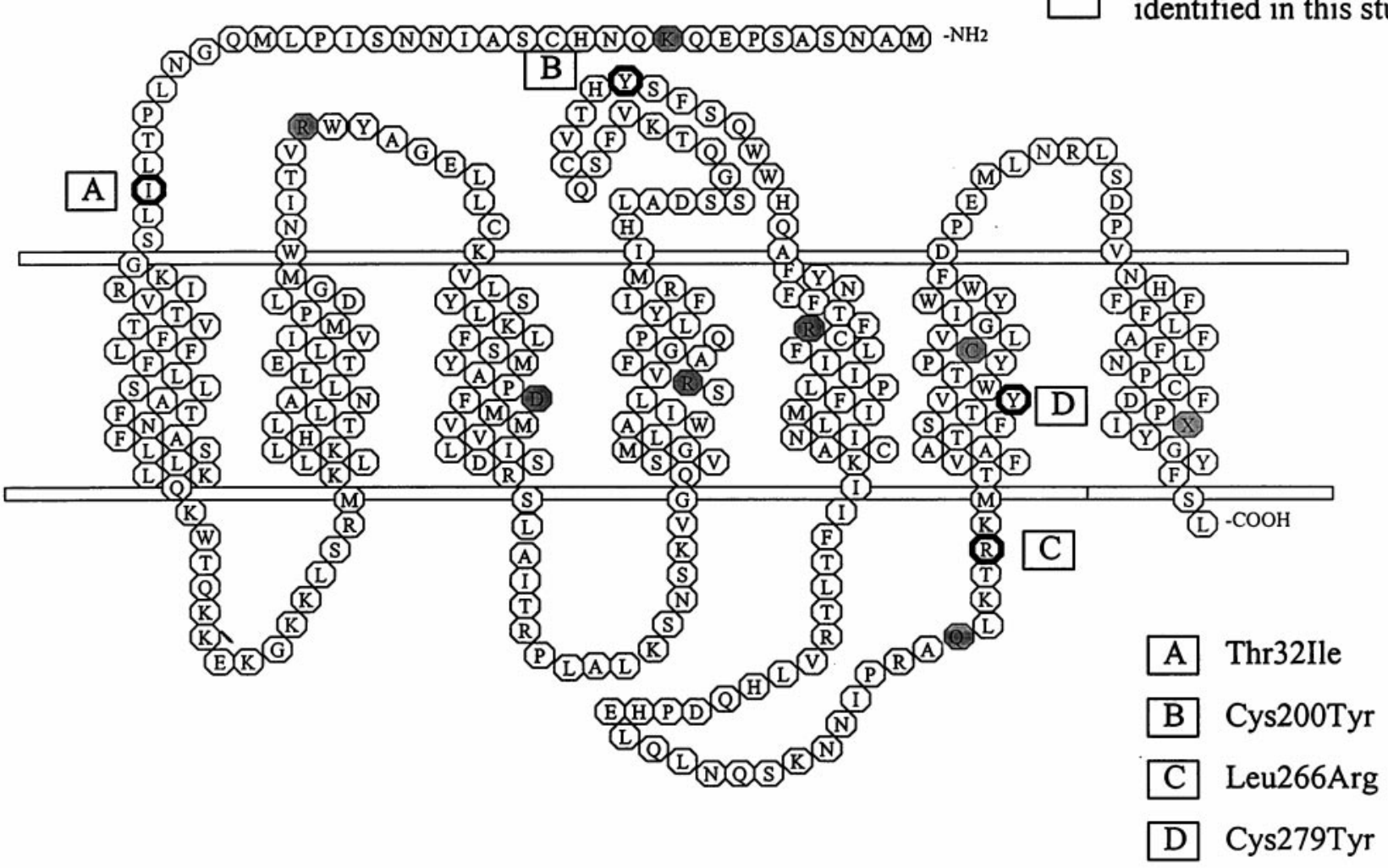

Novel mutation

dentified in this study

FIG. 2. Schematic of the GnRH receptor, adapted from Ref. 12. Mutations previously described in the literature are shaded in dark gray. Novel mutations identified in this study are outlined with a thick black line.

parability are involved, quantitative comparisons cannot be made. However, the presence of a normal serum level of FSH a priori cannot, by itself, account for the normal testicular growth of patient 5 . What is even more difficult to reconcile in patient 5 is his level of testicular growth in the face of hypogonadal testosterone levels, suggesting that other factors, perhaps gonadotropin independent, may also play an important role in gonadal development. Further data from our group has demonstrated the subsequent development of gonadotropin pulsatility in patient 5 after hCG stimulation, suggesting an effect of testosterone, whether direct or indirect, in modulating pituitary responsiveness to $\mathrm{GnRH}$ (Pitteloud N., P. A. Boepple, S. DeCruz, S. B. Valkenburgh, W. F. Crowley, and F. J. Hayes, submitted for publication).

Studying patients with shared GNRHR mutations also provides some important insights. Patient 5 with his homozygous Gln ${ }^{106}$ Arg mutation demonstrated no LH pulses on frequent blood sampling, yet he appears to be the least affected proband phenotypically in this patient cohort. Patient 3 shares one mutation $\left(\mathrm{Gln}{ }^{106} \mathrm{Arg}\right)$ with patient 5, whereas her other allele contains the novel missense mutation, $\mathrm{Leu}^{266} \mathrm{Arg}$, in the third intracellular loop. She presented with breast development, measurable gonadotropins and $\mathrm{E}_{2}$, and three LH pulses in $12 \mathrm{~h}$. Patient 1 also has the Gln ${ }^{106} \mathrm{Arg}$ mutation, whereas her second allele contains the mutation $\mathrm{Arg}^{262} \mathrm{Gln}$, also located in the third intracellular loop.

Although patient 1 presented with lower baseline gonadotropins and $E_{2}$, she did have pulsatile LH activity (five pulses over $12 \mathrm{~h}$ ). Although patients 3 and 5 had modest responses to a single bolus of $100 \mu \mathrm{g} \mathrm{GnRH}$ iv, patient 1 had no gonadotropin response. Therefore, in patients with GNRHR mutations, a gonadotropin response, albeit small, to a single pharmacological GnRH stimulation test seems to bear a loose correlation to phenotype, whereas pulsatile LH activity (as obtained in these 12-h windows) does not bear a clear relationship to the clinical presentation.

Although studying patients with identical GNRHR mutations is important, genotype/phenotype correlations are not easy to make, whether comparing identical genotypes across sexes or within a family. For example, patient 1 has the identical genotype $\left(\mathrm{Gln}{ }^{106} \mathrm{Arg}, \mathrm{Arg}^{262} \mathrm{Gln}\right)$ as the first patient reported with a GNRHR mutation, a male with partial puberty, 8-cc testes, spermatogenesis, normal gonadotropin increments to $100 \mu \mathrm{g}$ GnRH administered iv, and low amplitude LH pulsations every $2 \mathrm{~h}$ (10). Yet, patient 1 had absence of breast development, one nonestrogen-induced menstrual bleed, no gonadotropin responses to $100 \mu \mathrm{g} \mathrm{GnRH,} \mathrm{iv,} \mathrm{and}$ erratic low amplitude LH pulsations, suggesting that patient 
1 had a more severe phenotype, at least from a neuroendocrine perspective (31). Other reports in the literature describe different gender discrepancies. For example, two sisters with breast development had gonadotropin levels that responded to a single injection of $\mathrm{GnRH}$, whereas their brother with complete IHH had no gonadotropin response (13). Therefore, there may be sexually dimorphic responses to GNRHR mutations at both pituitary and gonadal levels. Although continued studies may help to elucidate further correlations, it is clear that no single clinical trait can be used to include or exclude the presence of a GNRHR mutation except the presence of anosmia.

In a previous screening study without subclassification of phenotype or mode of inheritance (11), GNRHR mutations were identified in just 1 of 46 patients with normosmic $\mathrm{IHH}$, yielding a frequency of GNRHR mutations of $2.2 \%$. The current report not only classifies patients on the basis of smell, but also on the complexity of phenotype (i.e. partial vs. complete hypogonadotropic hypogonadism) and the presumed mode of inheritance (i.e. dominant, recessive, X-linked, sporadic). In this cohort of 108 patients, 5 individuals had GNRHR mutations. When these patients were rephenotyped on the basis of smell, all 5 patients with GNRHR mutations were in the normosmic group ( 5 of 48 , or $10.4 \%$ ). When those 48 normosmic IHH probands were recategorized according to the mode of inheritance, 5 appeared to be from autosomal recessive kindreds, whereas 18 had no familial involvement. Two of the 5 probands with GNRHR mutations (patients 1 and 4) were from an autosomal recessive subgroup $(n=5)$, yielding a frequency of 2 of 5 , or $40 \%$. Therefore, although the number of cases with recessive inheritance was small $(\mathrm{n}=$ 5), the proportion of cases with GNRHR mutations within that subgroup was high $(40 \%)$. Viewed from another perspective, it is likely that another gene(s) accounts for autosomal recessive IHH. The remaining 3 probands with GNRHR mutations $(2,3$, and 5) were sporadic, yielding a frequency of 3 of 18 , or $16.7 \%$, in normosmic congenital IHH.

That the subtype of IHH (congenital vs. adult onset, IHH vs. KS) and mode of inheritance may serve as important guideposts for genetic testing has important implications for clinical practice. For example, the presence of a GNRHR mutation is not necessarily a contraindication to the use of exogenous, pulsatile GnRH, albeit at higher doses (31). Such therapy reduces the risk of multiple gestation in individuals seeking ovulation induction (35). In addition, patients with GNRHR mutations are unlikely to pass IHH onto their children, an increasingly important consideration for couples pursuing fertility therapy.

In summary, this study examines the frequency and distribution of GNRHR mutations in a large, heterogeneous population of patients with IHH. Patients bearing mutations demonstrate a broad range of $\mathrm{IHH}$, from complete to partial defects. Receptor mutations may account for a larger proportion of cases of IHH than previously appreciated. Patients with autosomal recessive or sporadic normosmic $\mathrm{IHH}$ should be considered candidates for screening.

\section{References}

1. Franco B, Guioli S, Pragliola A, et al. 1991 A gene deleted in Kallmann's syndrome shares homology with neural cell adhesion and axonal path-finding molecules. Nature. 353:529-536.

2. Legouis R, Hardelin JP, Levilliers J, et al. 1991 The candidate gene for the $\mathrm{X}$-linked Kallmann syndrome encodes a protein related to adhesion molecules. Cell. 67:423-435.

3. Legouis R, Lievre CA, Leibovici M, Lapointe F, Petit C. 1993 Expression of the KAL gene in multiple neuronal sites during chicken development. Proc Natl Acad Sci USA. 90:2461-2465.

4. Habiby RL, Boepple P, Nachtigall L, Sluss PM, Crowley Jr WF, Jameson JL. 1996 Adrenal hypoplasia congenita with hypogonadotropic hypogonadism. Evidence that DAX-1 mutations lead to combined hypothalamic and pituitary defects in gonadotropin production. J Clin Invest. 98:1055-1062.

5. Seminara SB, Achermann JC, Genel M, Jameson JL, Crowley Jr WF. 1999 $\mathrm{X}$-Linked adrenal hypoplasia congenita: a mutation in DAX1 expands the phenotypic spectrum in males and females. J Clin Endocrinol Metab. 84:4501-4509.

6. Tabarin A, Achermann JC, Recan D, et al. 2000 A novel mutation in DAX1 causes delayed-onset adrenal insufficiency and incomplete hypogonadotropic hypogonadism. J Clin Invest. 105:321-328.

7. Kakar SS, Musgrove LC, Devor DC, Sellers JC, Neill JD. 1992 Cloning, sequencing, and expression of human gonadotropin releasing hormone (GnRH) receptor. Biochem Biophys Res Commun. 189:289-295.

8. Chi L, Zhou W, Prikhozhan A, et al. 1993 Cloning and characterization of the human GnRH receptor. Mol Cell Endocrinol. 91:R1-R6.

9. Whitcomb RW, Crowley Jr WF. 1990 Clinical review 4: diagnosis and treatment of isolated gonadotropin-releasing hormone deficiency in men. J Clin Endocrinol Metab. 70:3-7.

10. de Roux N, Young J, Misrahi M, et al. 1997 A family with hypogonadotropic hypogonadism and mutations in the gonadotropin-releasing hormone receptor. N Engl J Med. 337:1597-1602.

11. Layman LC, Cohen DP, Jin M, et al. 1998 Mutations in gonadotropin-releasing hormone receptor gene cause hypogonadotropic hypogonadism. Nat Genet. 18:14-15.

12. Caron P, Chauvin S, Christin-Maitre S, et al. 1999 Resistance of hypogonadic patients with mutated GnRH receptor genes to pulsatile GnRH administration. J Clin Endocrinol Metab. 84:990-996.

13. de Roux N, Young J, Brailly-Tabard S, Misrahi M, Milgrom E, Schaison G. 1999 The same molecular defects of the gonadotropin-releasing hormone receptor determine a variable degree of hypogonadism in affected kindred. J Clin Endocrinol Metab. 84:567-572.

14. Kottler ML, Chauvin S, Lahlou N, et al. 2000 A new compound heterozygous mutation of the gonadotropin-releasing hormone receptor (L314X, Q106R) in a woman with complete hypogonadotropic hypogonadism: chronic estrogen administration amplifies the gonadotropin defect. J Clin Endocrinol Metab. 85:3002-3008.

15. Pralong FP, Gomez F, Castillo E, et al. 1999 Complete hypogonadotropic hypogonadism associated with a novel inactivating mutation of the gonadotropin-releasing hormone receptor. J Clin Endocrinol Metab. 84:3811-3816.

16. Spratt DI, O'Dea LStL, Schoenfeld D, Butler J, Rao PN, Crowley Jr WF. 1988 Neuroendocrine-gonadal axis in men: frequent sampling of LH, FSH, and testosterone. Am J Physiol. 254:E658-E666.

17. Santoro N, Butler J, Filicori M, Crowley Jr WF. 1988 Alterations of the hypothalamic GnRH interpulse interval sequence over the normal menstrual cycle. Am J Physiol. 255:E696-E701.

18. Nachtigall LB, Boepple PA, Pralong FP, Crowley Jr WF. 1997 Adult-onset idiopathic hypogonadotropic hypogonadism-a treatable form of male infertility. N Engl J Med. 336:410-415.

19. Waldstreicher J, Seminara SB, Jameson JL, et al. 1996 The genetic and clinical heterogeneity of gonadotropin-releasing hormone deficiency in the human J Clin Endocrinol Metab. 81:4388-4395.

20. Filicori M, Santoro N, Merriam GR, Crowley Jr WF. 1986 Characterization of the physiologic pattern of episodic gonadotropin secretion throughout the human menstrual cycle. J Clin Endocrinol Metab. 62:1136-1144.

21. Santen RJ, Bardin CW. 1973 Episodic luteinizing hormone secretion in man Pulse analysis, clinical interpretation, physiologic mechanisms. J Clin Invest. 52:2617-2628.

22. Welt CK, Adams JM, Sluss PM, Hall JE. 1999 Inhibin A and inhibin B response to gonadotropin withdrawal depends on stage of follicle development. J Clin Endocrinol Metab. 84:2163-2169.

23. Crowley Jr WF, Beitins IZ, Vale W, et al. 1980 The biologic activity of a potent analogue of gonadotropin-releasing hormone in normal and hypogonadotropic men. N Engl J Med. 302:1052-1057.

24. Filicori M, Butler JP, Crowley Jr WF. 1984 Neuroendocrine regulation of the corpus luteum in the human. Evidence for pulsatile progesterone secretion. J Clin Invest. 73:1638-1647. 
25. Whitcomb RW, O'Dea LStL, Finkelstein JS, Heavern DM, Crowley Jr WF. 1990 Utility of free alpha-subunit as an alternative neuroendocrine marker of gonadotropin-releasing hormone $(\mathrm{GnRH})$ stimulation of the gonadotroph in the human: evidence from normal and GnRH-deficient men. J Clin Endocrinol Metab. 70:1654-1661

26. Whitcomb RW, Sangha JS, Schneyer AL, Crowley Jr WF. 1989 Improved measurement of free alpha subunit of glycoprotein hormones by assay with use of a monoclonal antibody. Clin Chem. 34:2022-2025.

27. Abrams ES, Murdaugh SE, Lerman LS. 1990 Comprehensive detection of single base changes in human genomic DNA using denaturing gradient gel electrophoresis and a GC clamp. Genomics. 7:463-475.

28. Wartell RM, Hosseini SH, Moran Jr CP. 1990 Detecting base pair substitutions in DNA fragments by temperature-gradient gel electrophoresis. Nucleic Acids Res. 18:2699-2705.

29. Grosse R, Shoneberg T, Shultz G, Gudermann T. 1997 Inhibition of gonadotropin-releasing hormone receptor signaling by expression of a splice variant of the human receptor. Mol Endocrinol. 11:1305-1317.

30. Panchenko MP, Saxena K, Li Y, et al. 1998 Sites important for PLC $\beta 2$ acti- vation by the $G$ protein $\beta \gamma$ subunit map to the sides of the $\beta$ propeller structure. J Biol Chem. 23:28298-28304.

31. Seminara SB, Beranova M, Oliveira LMB, Martin KA, Crowley Jr WF, Hall JE. 2000 Successful use of pulsatile gonadotropin-releasing hormone $(\mathrm{GnRH})$ for ovulation induction and pregnancy in a patient with GnRH receptor mutations. J Clin Endocrinol Metab. 85:556-562.

32. Farfel Z, Bourne HR, Iiri T. 2000 The expanding spectrum of G protein diseases. N Engl J Med. 340:1012-1020.

33. Pasqualini RQ, Bur EG. 1950 Sindrome hipoandrogenico con gametogenesis conservada: clasificacion de la insuficiencis testicular. Rev Assoc Med Argent. 64:6.

34. McCullagh EP, Beck JC, Schaffenburg CA. 1953 A syndrome of eunuchoidism with spermatogenesis, normal urinary FSH and low or normal ICSH: "fertile eunuchs." J Clin Endocrinol Metab. 13:489-509.

35. Martin KA, Hall JE, Adams JM, Crowley Jr WF. 1993 Comparison of exogenous gonadotropins and pulsatile gonadotropin-releasing hormone for induction of ovulation in hypogonadotropic amenorrhea. J Clin Endocrinol Metab. 77:125-129.

\section{Joint Meeting-11th Annual Meeting of the European Neuropeptides Club (ENC) \& American Summer Neuropeptides Conference May 7-12, 2001 \\ Jerusalem (Kibbutz Ma'ale HaChamisha) and Tel Aviv, Israel}

For further information: Illana Gozes, Ph.D., Professor of Clinical Biochemistry, Sackler Faculty of Medicine, Tel Aviv University, Tel Aviv 69978, Israel. Phone: 972-3-640-7240; Fax: 972-3-640-8541; E-mail: igozes@post. tau.ac.il or meeting@unitours.co.il. 